\title{
Influence of Carbon Nanotubes on the Interlaminar Properties of Carbon Fiber Aluminum Metal Laminates
}

\author{
MADNI Shifa ${ }^{a^{*}}$, FAWAD Tariq ${ }^{b}$ and RASHEED Ahmed Baloch ${ }^{c}$ \\ Quality Management Directorate General, Pakistan Space and Upper Atmosphere \\ Research Commission (SUPARCO), 75270 Karachi, Pakistan \\ amadnishifa@yahoo.com, bt_fawad@hotmail.com, 'drrbaloch@hotmail.com
}

Keywords: CARALL, Interlaminar Properties, DCB Test, Short Beam Test, Flexural Test

\begin{abstract}
The present research work describes the fabrication and interlaminar properties testing of carbon fiber aluminum metal laminates (CARALL). CARALL was fabricated through hand layup process followed by compression molding technique and interlaminar properties were assessed through double cantilever beam (DCB) and flexural test. Different treatments were performed on the surface of aluminum alloy and parameters were optimized to ensure good adhesion between metal sheet and carbon composite layer. Pull-off adhesion test was performed to gauge the adhesion strength of epoxy resin on aluminum alloy sheet. Effect of Multi-wall carbon nanotubes (MWCNTs) was also investigated on the interlaminar properties of CARALL. Treated surface of aluminum alloy sheet was examined under optical and field emission scanning electron microscopy (FE-SEM). Porous surface was evident on aluminum sample due to surface treatment which contributes towards better adhesion between epoxy resin and metal surface through mechanical interlocking and diffusion mechanism. FE-SEM and stereo microscopy was also performed on fractured DCB samples and underlying fracture mechanism was discussed. Test results demonstrated that addition of MWCNTs deteriorated the interlaminar properties of CARALL by weakening the interface between treated aluminum surface and carbon composite.
\end{abstract}

\section{Introduction}

Globally, market demand for light weight and high strength materials has directed towards the development of new class of materials called fiber metal laminates (FML). FML is a kind of hybrid structure in which thin sheet of metal alloy is combined with fiber reinforced polymer matrix composite. Thin sheets of aluminum, titanium or magnesium alloys are usually used in combination with carbon, aramid or glass fiber reinforced polymer composites to fabricate FML of desired properties [1-2]. FML offers superior and tailorable mechanical properties over conventional composite and metallic materials alone. FML in fact, brings together the characteristics of both constitutes i.e. metal and composite. Owing to interesting mechanical and physical characteristics of FML, like high fatigue and impact resistance, increased facture toughness, low density, less repair and long maintenance period, makes this an important candidate for structural applications in various industries. Aerospace industry, in particular, fostering interest in FML due to its phenomenal characteristics and has successfully used FML in aircrafts like Airbus A380, Fokker 27 and Boeing C 17 [3-4]. Carbon fiber aluminum metal laminate (CARALL) is one of the variant of FML in which aluminum metal sheet is joined with carbon fiber reinforced polymer composite. CARALL was originally developed in early 90s in Delft University of Technology (Netherlands) [5] and produced in similar fashion like GLARE (Glass fiber Aluminum metal laminates) and ARALL (Aramid fiber Aluminum metal laminates). The combination of high strength and stiffness with superior impact bearing capabilities make CARALL ideal material for numerous structural applications demanding high impact and fatigue resistance [6-8]. High stiffness of carbon fiber composite reduces the crack growth rate through crack bridging mechanism and gives CARALL an edge over its competitors i.e., GLARE and ARALL.

Interfacial bonding between the composite and metallic layer is very crucial and dictates the overall performance of FML. FML experiences peel and shear stresses during service which may 
cause delamination at metal/composite interface. Moreover, Auffret et al. have reported that delamination occurs more frequently at fiber metal interface [9]. So, relatively low interlaminar shear strength cause the failure when subjected to interlaminar shear stresses [10]. Therefore, there is an intense need to improve the interlaminar shear strength of FML to avoid delamination failure, which in fact largely influenced by the adhesion between the metal sheet and composite layer [11]. An efficient surface treatment (either mechanical, chemical or electrochemical or combination of these) of the metallic sheet is essential to guarantee good interfacial bonding between metal/composite laminates [12]. Alternatively, interlaminar shear strength can also be enhanced by the addition of nanofillers at the interface or in the polymer matrix. For instance, many researchers [13-17] have reported improvement in interlaminar properties of composite materials by nanofillers addition. However, to the best of authors' knowledge, very little effort has been done to unveil the synergetic effect of nanofiller addition and surface modification on the interlaminar properties of CARALL [18].

Current study focuses on fabrication and mechanical testing of CARALL. Samples were fabricated through hand layup and compression molding technique followed by interlaminar shear testing to evaluate the interfacial bonding between carbon composite and aluminum alloy sheet. For the first time, mutual effect of aluminum surface modification and pristine MWCNTs addition at the interface was investigated on the interlaminar properties of CARALL.

\section{Materials and Methods}

Materials. Aluminum alloy 2024-T3 sheet of $0.5 \mathrm{~mm}$ thickness was chosen for fabrication of CARALL because of its widespread use in aerospace industry. MWCNTs (outer diameter $10-20 \mathrm{~nm}$, length 10-30 micron, purity level $>95 \%$, specific surface area $180-230 \mathrm{~m}^{2} / \mathrm{g}$ and bulk density $0.22 \mathrm{~g} / \mathrm{cm}^{3}$ ) were procured from Cheap Tube Inc. Carbon woven fabric used as reinforcement in epoxy matrix has following specification: areal density $325 \pm 5$, thickness $0.5 \pm 0.005 \mathrm{~mm}$, breaking strength $>270 \mathrm{Kg} / 5 \mathrm{~cm}$ in wrap direction, weave style satin $3,3 \mathrm{~K}$ tow and equal accounts of threads in warp and weft direction. Thermoset epoxy resin (Bisphenol-A) containing a reactive diluent was chosen as matrix because of its long pot life, low viscosity and multifunctional properties. Cycloaliphatic amine based hardener was used with epoxy resin in the ratio of 10:3.5 (by weight).

Surface Preparation. Different surface treatments were performed on aluminum alloy sheet before fabrication of CARALL samples to enhance adhesion between aluminum/composite layers. Surface treatment steps are briefly discussed in succeeding paragraphs.

Mechanical Abrasion. Aluminum sheet surface was degreased with detergent followed by cleaning with acetone to remove debris. Further, aluminum surface was mechanically abraded with 1200 grit size $\mathrm{SiC}_{3}$ paper to produce rough surface which in turns improves wettability and bonding.

Alkaline Cleaning and Deoxidation. To increase interfacial bonding between aluminum/composite layers, mechanically roughened sample was first immersed in $11 \mathrm{wt} \% \mathrm{NaOH}$ solution for the time period of $15 \mathrm{~min}$ at ambient temperature and then in deoxidant (10 wt $\%$ Potassium dichromate $+30 \mathrm{wt} \%$ Sulphuric acid $+60 \mathrm{wt} \%$ distilled water) for $15 \mathrm{~min}$ at $60^{\circ} \mathrm{C}$.

Anodization. Anodization is an electrochemical surface treatment process in which an oxide layer $\left(\mathrm{Al}_{2} \mathrm{O}_{3}\right)$ is formed on aluminum surface. Porous or barrier type oxide layer can be produce on aluminum surface through selection of electrolyte. Porous oxide film renders good interfacial bonding between adjoining surfaces and this can be ascertained by using acidic electrolyte (such as phosphoric acid or sulphuric acid). Phosphoric acid produces large size pores on metal surface and more commonly employed in aerospace industry for laminate formation. In this study, anodization of aluminum alloy sheet was carried out in an electrolytic cell by making aluminum sheet as anode and stainless steel sheet as cathode. Phosphoric acid (12 wt \%) in distilled water was used as an electrolyte. DC voltage of $30 \mathrm{~V}$ was applied between electrodes for 20-25 min, as shown in Fig. 1. 
Fabrication of CARALL Samples. CARALL was fabricated through hand-layup and compression molding technique. Two types of CARALL samples (CARALL-0 \& CARALL-CNTs) were fabricated in 1:1 configuration of aluminum alloy sheet with carbon composite ply. Surface treatments steps which were performed on aluminum alloy sheet during each type of CARALL fabrication is shown in Table 1.

CARALL-CNTs were fabricated by dispersing $0.2 \mathrm{wt} \%$ pristine MWCNTs in ethanol through bath sonication. Epoxy resin was mixed in MWCNTs contained solvent and sonicated at $80^{\circ} \mathrm{C}$ for $1 \mathrm{~h}$ to evaporate ethanol. Upon cooling, hardener was thoroughly mixed in this solution via magnetic stirrer to obtain a uniform dispersion. Carbon fabric was placed in the cavity of lower metallic die and MWCNTs filled epoxy resin was applied by the applicator brush. MWCNTs filled epoxy resin was also applied on aluminum alloy sheet and placed over the impregnated carbon fabric. The upper halve of the die was placed over the lower halve, aligned through guided pins and tightened in such a way that the excess resin drained out from the die outlets. Laminate was then cured in an autoclave at $80^{\circ} \mathrm{C}$ for $30 \mathrm{~min}, 100^{\circ} \mathrm{C}$ for $30 \mathrm{~min}$ and finally at $160^{\circ} \mathrm{C}$ for $2 \mathrm{~h}$. The cured samples were removed from the die and sides were trimmed. Similar process was also employed to produce CARALL-0 sample without MWCNTs addition.

Table 1. Steps involved in surface preparation of each type of aluminum sample

\begin{tabular}{ll}
\hline Sample ID & Aluminum surface preparation steps \\
\hline CARALL-0 & Abrasion + Alkaline cleaning \& deoxidation + Anodization \\
\hline CARALL-CNTs & Abrasion + Alkaline cleaning \& deoxidation + Anodization + MWCNTs \\
\hline
\end{tabular}

\section{Characterization Techniques}

Light microscopy (Optika, Italy) was performed on un-cured and cured matrix to examine the level of MWCNTs dispersion. A droplet of MWCNTs filled epoxy matrix was taken on glass slide for observation under microscope at 100x. The glass slides containing MWCNTs filled epoxy was cured in oven and again scanned under microscope to witness the effect of curing cycle on distribution of MWCNTs. Aluminum alloy sheet surface was also inspected under light microscope before and after surface treatments. Stereo macroscopy (Meiji, Japan) was carried out on fractured area of CARALL samples to study the failure mechanism.

Field Emission Scanning Electron Microscopy (FE-SEM) was performed on treated aluminum alloy sheet to determine the anodized depth and to observe the surface topography. Cross section of surface treated sample was prepared by standard grinding and polishing technique for measurement of anodized depth. Fractured samples after double cantilever beam testing were also examined under FE-SEM. Moreover, SEM was also performed to observe the interface of carbon composite and aluminum metal.

\section{Mechanical Testing}

Double Cantilever Beam (DCB) test samples were cut to size $(120 \mathrm{~mm}$ x $20 \mathrm{~mm})$ from fabricated CARALL panel. A PTFE (polytetrafluoroethylene) film of $63 \mathrm{~mm}$ length was inserted at the mid plane of aluminum/carbon interface during CARALL fabrication to create a delamination. Pair of metallic hinges was mechanically attached to sample end. Distance between loading points to the end of insert (crack initiation point) was $50 \mathrm{~mm}$. Sample cross section was spray painted and mark off with blue paint for monitoring of crack progression. Samples were tested on $10 \mathrm{kN}$ Universal Testing Machine (Lloyd, UK) at a speed of $1 \mathrm{~mm} / \mathrm{min}$ according to ASTM D5528. Crack length as a function of load-displacement was manually noted. Mode I interlaminar fracture toughness (GIc) was calculated from equation 2 using modified beam theory (MBT).

$$
\mathrm{GIc}=3 \mathrm{P} \delta / 2 \mathrm{~b}(\mathrm{a}+|\Delta|) .
$$


Where $\mathrm{P}$ is the load, $\delta$ is the opening displacement, $\mathrm{b}$ and $\mathrm{a}$ is the sample width and delamination length respectively. Whereas $\Delta$ was determined experimentally by generating least square plot of compliance $\mathrm{C}^{1 / 3}$ as a function of delamination length (a) as per standard.

Three-point bend test was performed to evaluate the flexural strength of fabricated CARALL. Testing was carried out on $150 \mathrm{kN}$ Universal Testing Machine (Tinius Olsen, UK) at a speed of $1 \mathrm{~mm} / \mathrm{min}$ in conformance to ASTM D790. Five samples of each kind were tested in such a way that aluminum side of the sample was kept upside (i.e. it faces the plunger). Digital image correlation (DIC) technique was employed for accurate measurement of mid span displacement.

Short beam test was performed as per BS EN ISO 14130 standard. The test setup consists of a short beam sample of rectangular cross section loaded in three-point bending mode in such a way to ensure interlaminar shear failure. Tests were conducted on $150 \mathrm{kN}$ Universal Testing Machine (Tinius Olsen, UK) at a speed of $1 \mathrm{~mm} / \mathrm{min}$. Five samples of each type of CARALL were tested with aluminum face upside while composite side lie on support roller.

Pull-off strength experiment was conducted to assess the quality of epoxy matrix adhesion on aluminum metal sheet. Layer of epoxy approximately $1 \mathrm{~mm}$ (with and without CNTs) was applied on anodized aluminum sheet by hand layup and cured in oven. The epoxy was pulled from substrate by a special fixture in accordance with ASTM D 4541-95. Average of 5 readings of pull-off strength is reported here.

\section{Results and Discussion}

Light Microscopy. Fig. 1(a, b) represents the optical micrographs of MWCNTs filled epoxy matrix showing CNTs dispersion in uncured and cured state respectively. In uncured state, MWCNTs were uniformly distributed throughout the matrix and less amount of sub-micron size aggregates were seen in Fig. 3(a). However, curing of epoxy resin is lengthy polymerization process during which CNTs find time to re-entangle because of electrostatic forces between them before their motion seizes. Hence aggregates of MWCNTs were observed in cured state as shown in Fig. 1(b).

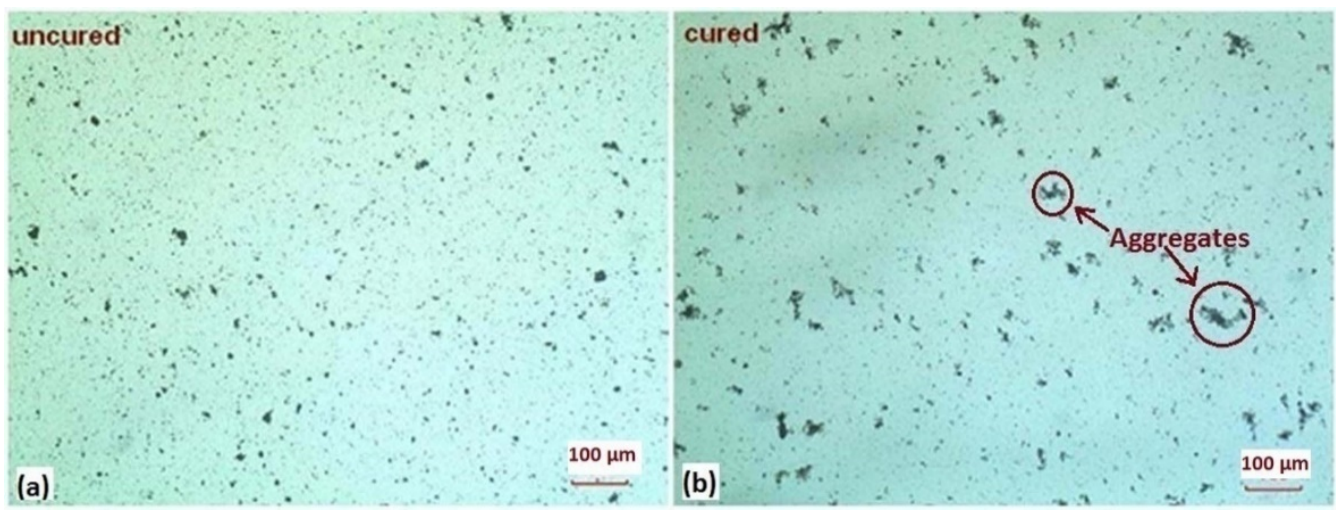

Fig. 1. Optical micrographs of MWCNTs filled epoxy matrix showing MWCNTs dispersion in (a) uncured and (b) cured state

Fig. $2(a, b)$ shows optical micrographs of aluminum alloy sheet after grinding with sand paper and after anodizing. As-received aluminum alloy sheet has settled aluminum oxide layer which hinders good adhesion with another material. In order to ensure good bonding, this nonporous oxide layer $\left(\mathrm{Al}_{2} \mathrm{O}_{3}\right.$ film $)$ needs to be removed. Mechanical abrasion partially removes oxide layer and creates active sites for chemical attacks. Chemical treatments followed by anodizing completely removes barrier oxide layer and generate irregular porous structure (Fig. 2b) on the surface of aluminum alloy sheet which improves adhesion through mechanical interlocking and diffusion mechanisms. 


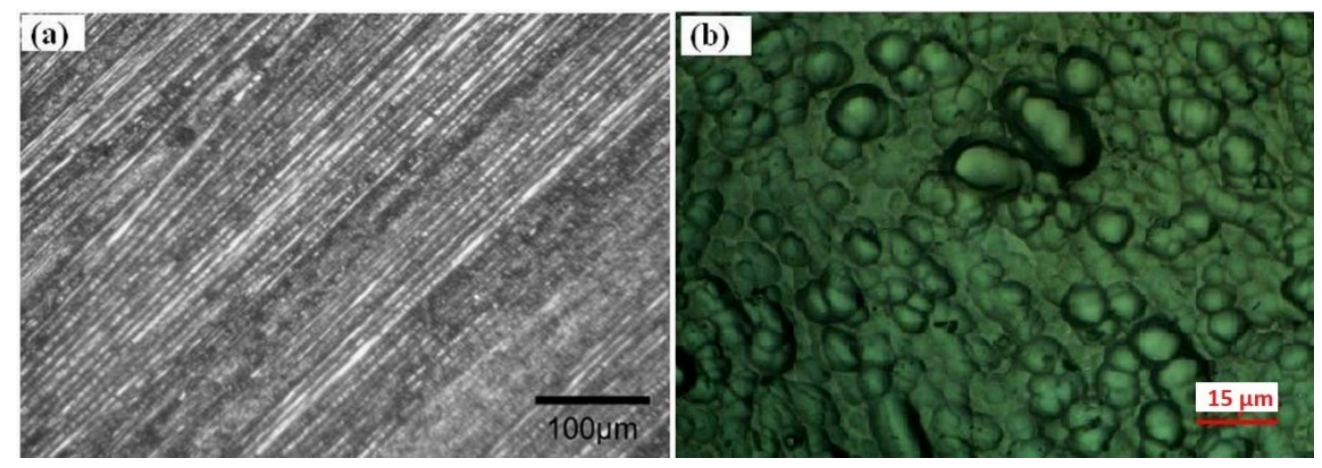

Fig. 2. Optical image of aluminum alloy sheet after (a) grinding with emery paper and (b) after anodizing

Field Emission Scanning Electron Microscopy (FE-SEM). Fig. 3(a, b) shows the FE-SEM image of anodized aluminum surface and cross-section respectively. Porous structure is visible attributed to electrochemical treatments performed on its surface. Pore diameters ranges in between 2-10 um and layer thickness was around $30 \mathrm{um}$, as shown in Fig. 3(b). It was observed that depth of anodized layer increase with anodizing time which might adversely affect the adhesion properties. Porous aluminum structure is responsible for better resin infiltration during impregnation process of CARALL manufacturing which ultimately increases the interfacial bonding strength. Arrow heads in Fig. 3(c) shows the defect free interface of carbon composite and metal layer which is mandatory requirement for better adhesion between the layers. While Fig. 3(d) shows the agglomerates of pristine MWCNTs embedded in epoxy matrix on aluminum metal surface after DCB testing. These agglomerates are basically responsible for weakening the interface between the layers of CARALLCNTs sample.

Double Cantilever Beam (DCB) Testing. Fig. 4(a) shows plots of GIc as a function of delamination length (a) for both type of CARALL samples. A typical stick-slip fracture behavior was observed during delamination growth in both test samples which is common in epoxy based composite laminates [19]. During testing of samples, GIc first increases and then stabilizes with further increase in delamination length in all cases. Stick-slip failure mode follows crack growth and crack arrest mechanism which is indicative of unstable crack propagation. In case of CARALL0 , GIc first increase monotonically and then stabilizes; very little drop in GIc value was recorded in this case. Contrary to our expectations, drop in GIc value was more significant during crack propagation leading to more catastrophic fracture in case of CARALL-CNTs (Fig. 4a). Highest value of critical GIc $\left(536 \pm 5 \mathrm{~J} / \mathrm{m}^{2}\right)$ was achieved in CARALL-0 whereas relatively lower value of critical GIc $\left(414 \pm 5 \mathrm{~J} / \mathrm{m}^{2}\right)$ was observed in CARALL-CNTs (Table 2). Results exhibited that the addition of pristine MWCNTs in anodized sample has somehow decreased the critical value of GIc by $22.7 \%$.

Flexural Testing. Fig. 4(b) shows flexural stress vs. strain curves of fabricated CARALL. Highest flexural strength was achieved in CARALL-0 whereas decrease in flexural strength was witnessed in CARALL-CNTs sample. Reduction in flexural strength was owed to the addition of MWCNTs in the anodized sample. Similar trend was also observed in flexural modulus. About $15 \%$ decline in flexural modulus was noted in CARALL-CNTs sample. Results indicated that the introduction of MWCNTs $(0.2$ wt. \%) in anodized sample adversely affects the flexural properties as presented in Table 2.

Short Beam Testing. Interlaminar shear strength (ILSS) of CARALL was estimated through short beam testing. Aluminum layer of CARALL experiences compressive stress while composite layer bears tensile load. Delamination typically propagates through the aluminum/composite interface as observed in our case also (Fig. 4c). This failure takes place due to shear forces between the layers indicating relatively weak bonding at the interface. Fig. 4(d) represents the ILSS of fabricated CARALL-0 and CARALL-CNTs. Maximum ILSS of average $36 \pm 1.2 \mathrm{MPa}$ has been witnessed in CARALL-0 samples whereas ILSS of CARALL-CNTs was $30 \pm 1.2 \mathrm{MPa}$. Addition of $0.2 \mathrm{wt} \%$ 
MWCNTs has unexpectedly decreased the ILSS by $16.6 \%$. This reduction in ILSS was attributed to the fact that pristine MWCNTs forms agglomerates as shown in Fig. 3d which act as stress concentration points. The agglomeration in the interfacial region in fact weakens the interface and provides easy path for crack to progress. The influence of using functionalized MWCNTs on interfacial shear strength needs further detailed investigation.
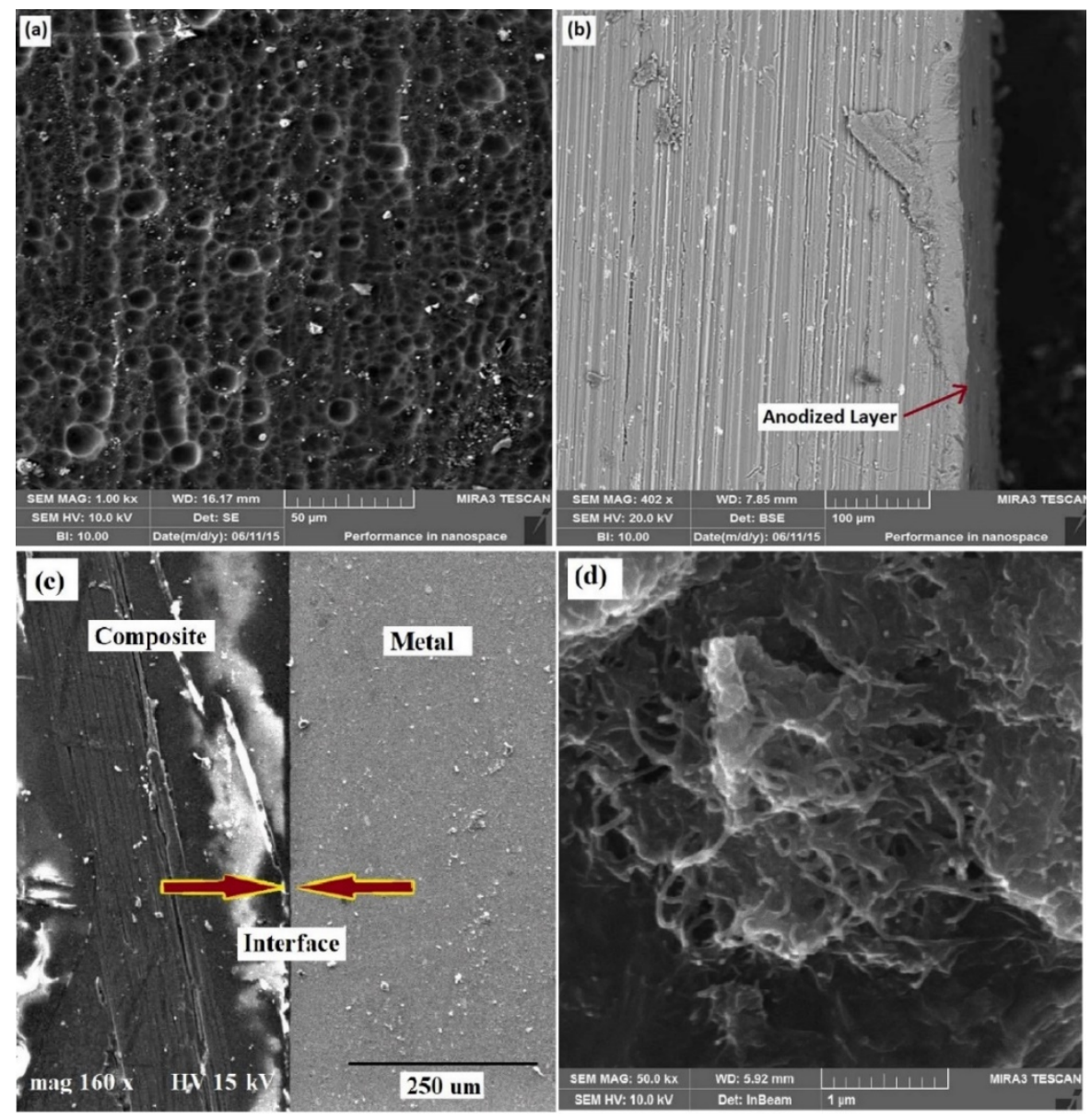

Fig. 3. FE-SEM image of anodized aluminum alloy sheet showing (a) Surface (porous structure) (b) Crosssection (thickness of anodized layer) (c) Interface between composite \& metal layer (d) Agglomerates of MWCNTs embedded in epoxy matrix on aluminum metal surface

Pull-off adhesion Testing. Fig. 5(a, b) shows the photograph of epoxy coating from the aluminum alloy substrate. Pull-off strength was calculated to be $1.57 \pm 0.3 \mathrm{MPa}$ and $1.31 \pm 0.3 \mathrm{MPa}$ for CARALL-0 and CARALL-CNTs sample respectively (Table 2). Arrow head on the substrate shows the detached part of coating material from aluminum alloy which was attached on the surface of dolly (Fig. 5a). One can see from the Fig. 5(a) that dolly completely removed the coating from aluminum alloy substrate. While Fig. 5 (b) shows the cracking of epoxy coating at aluminum substrate which clearly indicates that dolly did not remove the coating materials fully from aluminum substrate due to failure of bonding agent. Which directs that coating adhesion strength on aluminum substrate is quite greater than strength of bonding agent. Arrow head in Fig. 5(b) represents leftovers of coating material at the substrate and replica of it on dolly. Results supported by the photographs suggested that the anodized surface offers stronger bonding in comparison to inclusion of CNTs on anodized surface.

Crack Growth and Fracture Surface Analysis. Fig. 6(a, b) illustrates the optical micrographs of peeled-off region of aluminum surface after DCB test. Large amount of residues and impressions of composite layer were observed in CARALL-0 (Fig. 6a) as compared to CARALL-CNTs (Fig. 6b) which reflects strong interfacial bonding between aluminum and composite in CARALL-0. Improvement in interfacial strength in turn raises the fracture toughness. Microscopic examination of the fractured surfaces confirmed these finding; as highest fracture energy was observed in 
CARALL-0 (Fig. 4a). Fractured aluminum surfaces were further examined under FE-SEM to elucidate the high fracture toughness. Fig. 6c shows fractured carbon fibers adhered to aluminum surface indicating cohesive failure in CARALL-0 due to presence of micro-holes at aluminum surface. In Fig. 6d, epoxy leftover was observed at aluminum surface without fibers which is also indicative of good bonding. However, amount of interlaminar strength was decreased by the addition of pristine MWCNTs in CARALL. In authors' opinion, CNTs agglomerates serve as potent sites for crack initiation. Another reason could be blocking of surface pores by MWCNTs clusters which adversely affect the infiltration of epoxy in these thereby reducing mechanical interlocking and bond formation. To sum up, the addition of MWCNTs was found to deteriorate the interlaminar properties by weakening the aluminum/composite interface. The possibility of using functionalized MWCNTs to strengthen the interface cannot be ruled out and hence demands further exploration.

Fig. 7 shows the crack propagation path in CARALL after DCB testing observed under stereo microscope. During the DCB testing, with increasing load the crack advances in zigzag manner as shown by arrow head in Fig. 7(a, b) respectively leading to improve fracture resistance. In fact, advancing crack has to surmount obstacles at metal/composite interface by following zigzag path which increases the fracture area resulting improvement in interlaminar shear strength. It is observed that the crack propagates in a relatively straight path along the metal/composite interface in case of CARALL-CNTs sample as shown by arrow head in Fig. 7(b) resulting inferior fracture resistance as compared to CARALL-0. Moreover, crack bridging effect was also observed in CARALL-0 as shown in Fig. 7(c) which hinders the delamination growth causing improvement in fracture toughness.

(a)

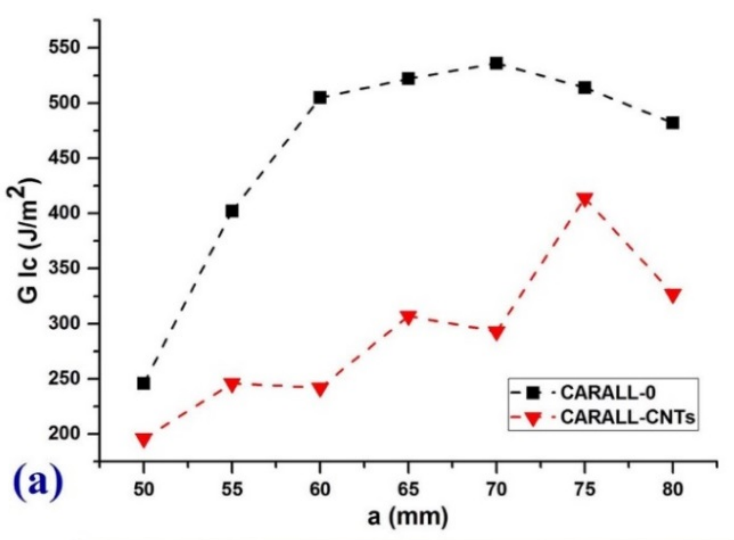

(c)

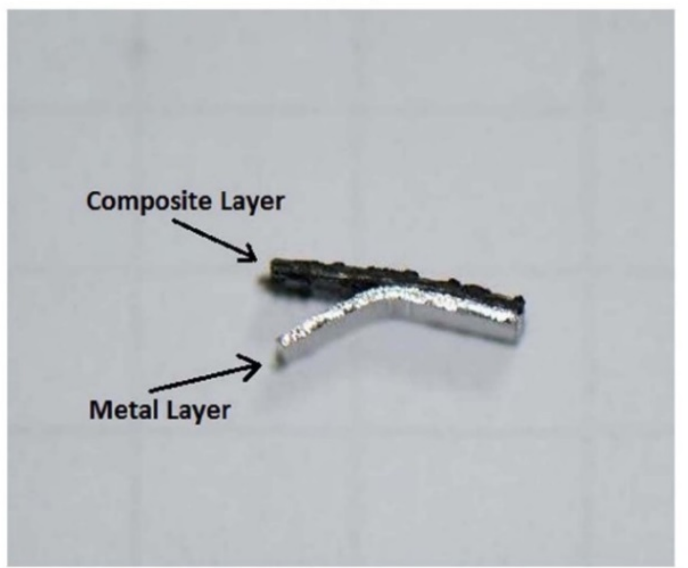

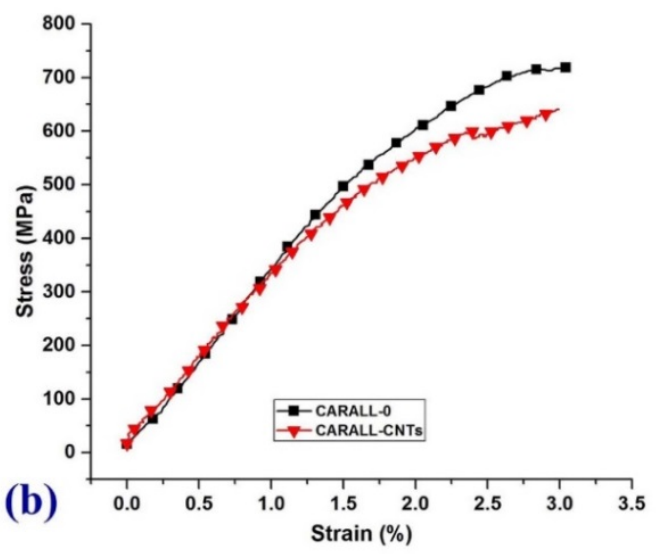

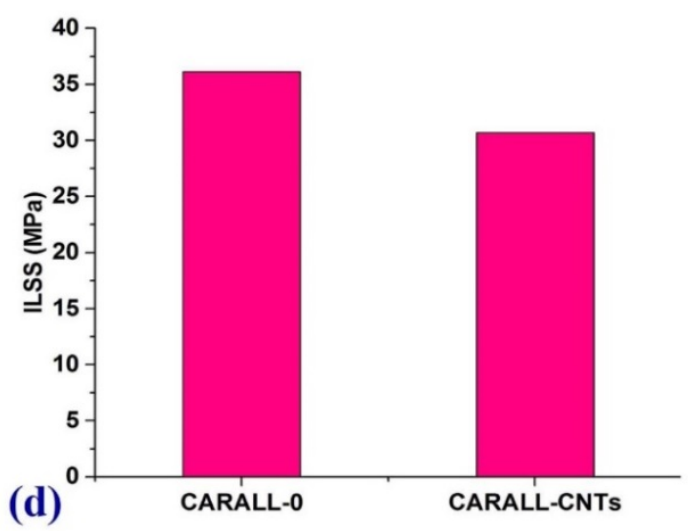

Fig. 4. Plot of (a) DCB test results (b) Flexural test results

(c) Photo of shear failure (d) Short beam test results 


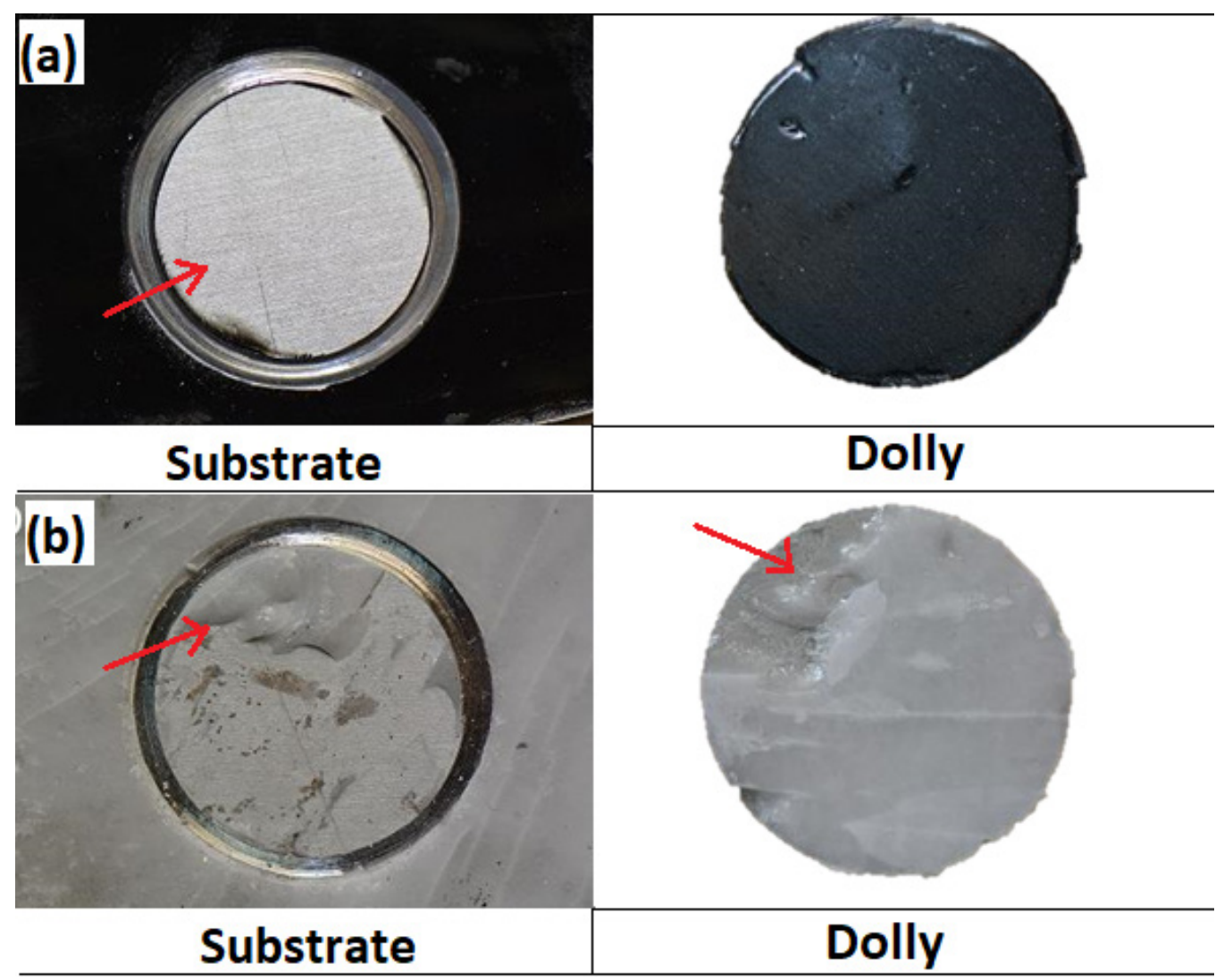

Fig. 5. (a, b) Pull off adhesion test-Showing the coating removal in (a) CARALL-0 and (b) CARALL-CNTs

Table 2. Influence of MWCNTs on mechanical properties of CARALL-0 \& CARALL-CNTs

\begin{tabular}{cccc}
\hline $\begin{array}{c}\text { Mechanical } \\
\text { Properties }\end{array}$ & CARALL-0 & $\begin{array}{c}\text { CARLL- } \\
\text { CNTs }\end{array}$ & Remarks \\
\hline $\begin{array}{c}\text { Mode I fracture } \\
\text { toughness }\left(\mathrm{J} / \mathrm{m}^{2}\right)\end{array}$ & $536 \pm 5$ & $414 \pm 5$ & $22.7(\%)$ change in GIc value was witnessed \\
\hline $\begin{array}{c}\text { Avg. Flexural } \\
\text { Strength (MPa) }\end{array}$ & $703.6 \pm 3.5$ & $579.4 \pm 3.5$ & $\begin{array}{l}17.6(\%) \text { change in flexural strength was } \\
\text { observed }\end{array}$ \\
\hline $\begin{array}{c}\text { Avg. Flexural } \\
\text { Modulus (GPa) }\end{array}$ & $33.1 \pm 1$ & $28.1 \pm 1$ & $15.1(\%)$ change in Flexural modulus was noted \\
\hline $\begin{array}{c}\text { Interlaminar } \\
\text { Shear Strength } \\
\text { (MPa) }\end{array}$ & $36 \pm 1.2$ & $30 \pm 1.2$ & $16.6(\%)$ change in ILSS was observed \\
\hline $\begin{array}{c}\text { Pull-off adhesion } \\
\text { strength (MPa) }\end{array}$ & $1.57 \pm 0.3$ & $1.31 \pm 0.3$ & $\begin{array}{l}10.5(\%) \text { change in adhesion strength was } \\
\text { noticed }\end{array}$ \\
\hline
\end{tabular}




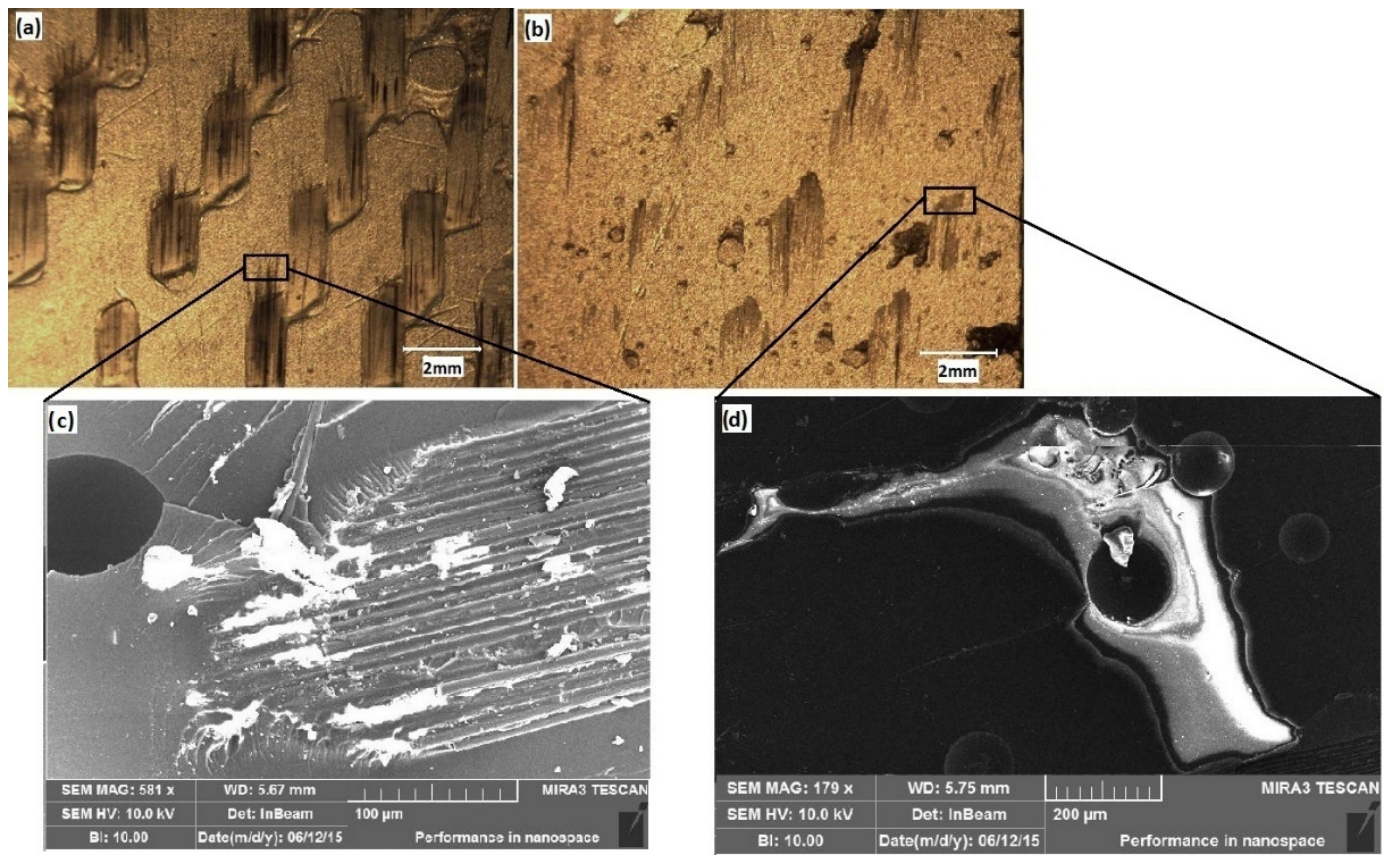

Fig. 6. Optical stereomicroscopic image of (a) CARALL-0 (b) CARALL-CNTs and FE-SEM image of (c) CARALL-0 (e) CARALL-CNTs of aluminum surface after DCB test

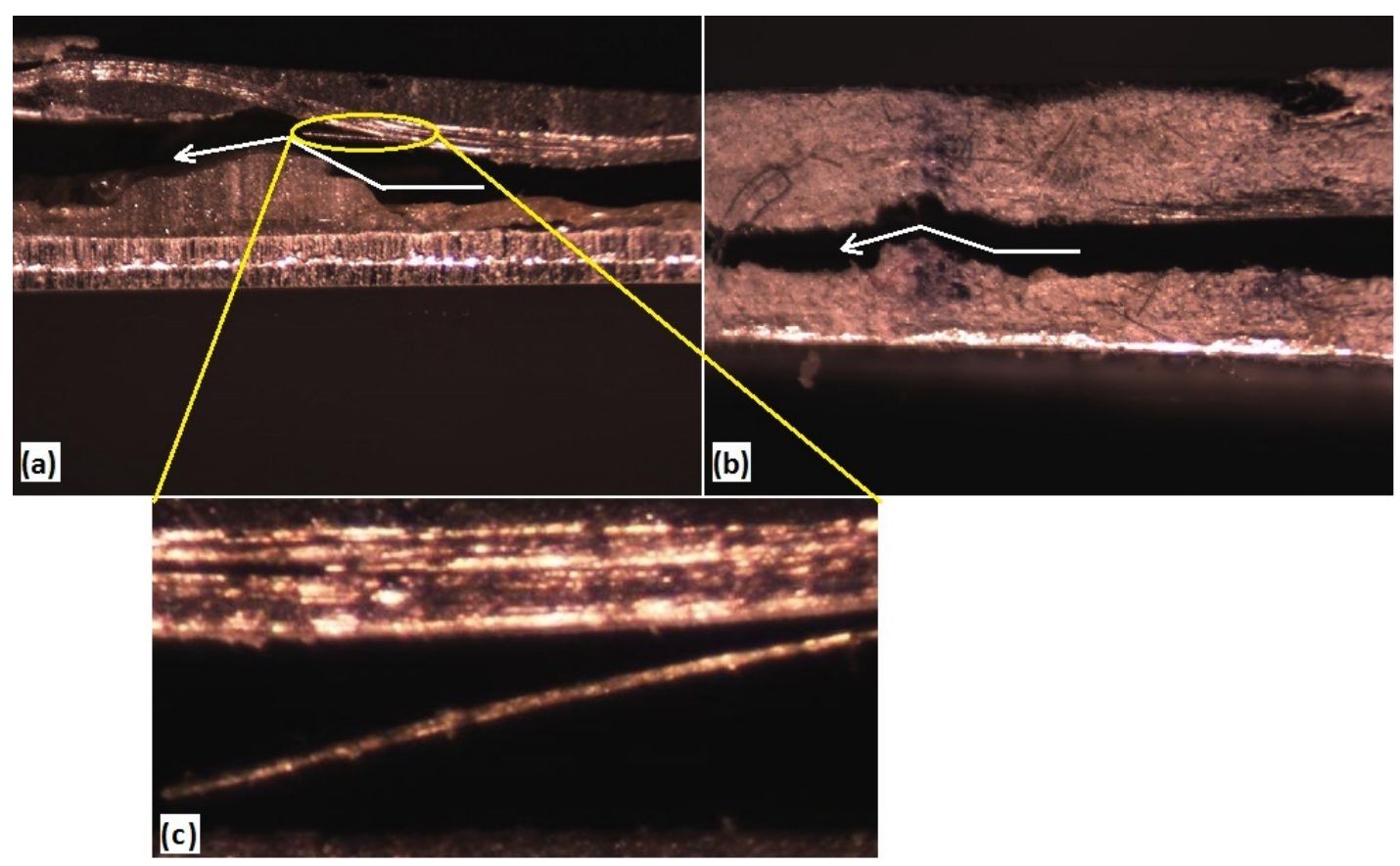

Fig. 7. Optical image of crack propagation path after DCB testing in (a) CARALL-0(b) CARALL-CNTs (c) crack bridging phenomena in CARALL-0

\section{Conclusion}

This research work was conducted to investigate the interlaminar properties of CARALL through optimization of surface preparation methods. Furthermore, consequence of pristine MWCNTs addition in aluminum/carbon composite interfacial region on interlaminar properties was also studied. Based on experimental results, following conclusions are drawn:

1) From mechanical testing results, it can be concluded that surface modification through anodization of aluminum surface resulted promising interlaminar properties. For example, CARALL-0 showed flexural strength upto 703.5 $\pm 3.5(\mathrm{MPa})$, critical fracture toughness upto $536 \pm 5\left(\mathrm{~J} / \mathrm{m}^{2}\right)$ and ILSS upto $36 \pm 1.2(\mathrm{MPa})$. 
2) Incorporation of pristine MWCNTs in anodized sample decreased the critical fracture toughness up to $22.7 \%$, ILSS up to $16.6 \%$ and flexural strength up to $17.6 \%$ in comparison to CARALL-0.

3) SEM results confirmed the formation of porous structure which is responsible for strong interfacial bonding through mechanical interlocking and diffusion mechanism.

4) Optical and SEM microscopy revealed formation of MWCNTs agglomerates which acted as stress concentration points.

5) Analysis of fracture surface after DCB test reveals that crack advances in zigzag fashion in CARALL-0 as compare to CARALL-CNTs, resulting superior interlaminar properties. Moreover, large amount of composite remnants on aluminum surface is also a symbolic of strong interfacial bonding between the layers in CARALL-0 sample.

6) Pull-off strength test signify that MWCNTs filled epoxy has lower adhesion with aluminum substrate than epoxy without MWCNTs.

\section{Acknowledgement}

Authors would like to thank Chairman SUPARCO for approval and provision of facilities.

\section{References}

[1] I. Dinca, A. Stefan, A. Stan, Aluminum/glass fiber and aluminum/ carbon fiber hybrid laminates, Incas. Bulle., 2 (2010) 33-39.

[2] J.J.C. Remmers, R. de Borst, Delamination buckling of fiber-metal laminates Compo. Sci. Tech., 61 (2001) 2207-2213.

[3] T. Sinmazcelik, E. Avcu, M. Ozgur Bora, O. Coban, A review: Fiber metal Laminates, background, bonding types and applied test methods, Mater. Desi., 32 (2011) 3671-3685.

[4] S. M. Ahmed, C. Anil Kumar, Mechanical Characterization and analysis of perforated fiber metal lamiates, Inter. J. Eng. Tren. Tech., 13 (2014) 216-224.

[5] R. A. Silva, Processamento e Caracterização de Compósitos Híbridos Fibra/Metal, PhD Thesis, Instituto Tecnológico de Aeronáutica - ITA/CTA, São José dos Campos, São Paulo, Brazil (2006).

[6] J. Xue, W.-X. Wang, Y. Takao, T. Matsubara, Reduction of thermal residual stress in carbon fiber aluminum laminates using a thermal expansion clamp, Comp. Part A, 42 (2011) 986-992.

[7] R. C. Alderliesten, R. Benedictus, Fiber/Metal Composite Technology for Future Primary Aircraft Structures, J. Aircr., 45(2008) 1182-1189.

[8] E. C. Botelho, R. A. Silva, L. C. Paradini, M. C. Rezende, A review on the development and the properties of continuous fiber/epoxy/aluminum hybrid composites for aircraft structures, Mater. Res., 9(2006) 247-256

[9] A. Vlot, J.W. Gunnink, editors, Fibre Metal Laminates. Dordrecht: Springer Netherlands; 2001. doi:10.1007/978-94-010-0995-9.

[10] G. Hector, K. Juan, E. Perez, Short-beam shear fatigue behavior of fiber metal lamintes (Glare)" Intern. J. Fat., 13 (2016) 278-286.

[11]E. C. Botelho, L. L. Bourlegat, A. C. Ancelloti Junior, L. C. Pardini, Study of v-notch shear test in carbon fiber epoxy titanium laminates" 19th international congress on Mechanical engineering, Barasilia DF, November 5-9 (2007).

[12] G. A. Nitowski, Topographic and surface chemical aspects of the adhesion of structural epoxy resin to phosphorous oxo acid treated aluminum adherends, Doctors of Philosophy in Materials Engineering Science, Blucksburg Virginia, August 26, (1998). 
[13]N.A. Siddiqui, R.S.C. Woo, J.K. Kim, C.R.Y. Leung, A. Munir, Mode I interlaminar fracture behavior and mechanical properties of CFRPs with nanoclay-filled epoxy matrix, Comp. Part A, 38(2007) 449-60.

[14] V. Kostopoulos, P. Tsotra, P. Karapappas, S. Tsantzalis, A. Vavouliotis, T.H. Loutas, et al. Mode I interlaminar fracture of CNF or/and PZT doped CFRPs via acoustic emission monitoring, Comp. Sci. Tech., 67(2007) 822-8.

[15] T. Yokozeki, Y. Iwahori, S. Ishiwata, K. Enomoto., Mechanical properties of CFRP laminates manufactured from unidirectional prepregs using CSCNT-dispersed epoxy, Compo. Part A, 38 (2007) 449-60.

[16] R.M.H. Jen, Y.C. Tseng, C.H. Wu, Manufacturing and mechanical response of nanocomposite laminates, Compo. Sci Technol., 65 (2005) 775-9.

[17] Y. Li, N. Hori, M. Arai, N. Hu, Y. Liu, H. Fukunaga, Improvement of interlamiar Mechanical properties of CFRP laminates using VGCF, Compo. Part A, 40 (2009) 2004-2012.

[18]H. Ning, Y. Li and N. Hu, Improvement of mechanical interlaminar properties of CARALL based on nanofiller interface reinforcement and other fabrication techniques, 13th international conference on fracture, Beijing China, June 16-21, (2013).

[19]F. Inam, W.Y. Wong, M. Kuwata, and T. Peijs, Multiscale hybrid micro nano-composites based on carbon nanotubes and carbon fibers, Hindawi Publishing corporation, J. Nanomat., 25 (2010) Article ID 453420, 12 Pages. 